\title{
Haploidentical Hematopoietic Cell Transplantation Using Posttransplant Cyclophosphamide for Sézary Syndrome
}

\author{
Madoka Kanda-Kato Satoshi Yoshioka Takayuki Ishikawa \\ Department of Hematology, Kobe City Medical Center General Hospital, Kobe, Japan
}

\section{Keywords}

Haploidentical hematopoietic cell transplantation · Posttransplant cyclophosphamide .

Sézary syndrome

\begin{abstract}
Patients with advanced-stage mycosis fungoides (MF) and Sézary syndrome (SS) have a poor prognosis. Allogeneic hematopoietic cell transplantation (HCT) is a potentially curative treatment option; however, since most patients with MF/SS are elderly, they often have difficulty in finding HLA-matched donors. In recent years, HCT from HLA-haploidentical donors (haploHCT) using posttransplant cyclophosphamide (PTCy) as graft-versus-host disease prophylaxis has been conducted for patients without HLA-matched donors. Infectious complications, particularly cutaneous bacterial infections, are common among patients with MF/SS. The lower incidence of severe infectious complications after haplo-HCT than after an unrelated cord blood transplantation could lead to lower transplant-related mortality. Here, we report on a patient with SS who was treated successfully with haplo-HCT with PTCy. The patient has remained in complete remission for more than 24 months.

\section{Introduction}

Cutaneous T-cell lymphomas are a rare group of extranodal non-Hodgkin lymphoma. Mycosis fungoides (MF) is the most common form of cutaneous T-cell lymphoma, and Sézary syndrome (SS) is a leukemic variant associated with erythroderma [1]. Although many therapeutic options have been introduced for those with MF/SS, ranging from topical steroids to systemic chemotherapy and molecular targeted approaches, none of them can induce longterm remission or cure [2]. In particular, patients with advanced-stage MF/SS have a poor prognosis, with a reported median survival of 5 years or less [3]. 
Allogeneic hematopoietic cell transplantation (HCT) can yield durable remission in patients with refractory and progressive MF/SS; indeed, it is a potential cure [3]. However, the search for an HLA-matched donor can be time-consuming and, in many cases, unsuccessful.

In recent years, haploidentical HCT (haplo-HCT) using posttransplant cyclophosphamide (PTCy) as graft-versus-host disease (GVHD) prophylaxis has been conducted. Since almost every patient will have an HLA-haploidentical donor within a family, haplo-HCT is an attractive option for patients lacking an HLA-matched donor.

The European Society for Blood and Marrow Transplantation (EBMT) Lymphoma Working Party reports that patients with non-Hodgkin lymphoma (including follicular lymphoma, diffuse large B-cell lymphoma, mantle cell lymphoma, and T-cell lymphoma) who received haplo-HCT with PTCy had outcomes comparable with those who had matched sibling donors (MSD) and matched unrelated donors (MUD) [4]. However, few reports have examined haplo-HCT with PTCy for patients with MF/SS.

Here, we report on a case of SS who was treated successfully by haplo-HCT with PTCy. The patient has remained in complete remission (CR) for more than 24 months after transplantation.

\section{Case Report}

The patient was a 63-year-old Japanese woman who was referred to the hospital in 2016. She had a 10-year history of pruritic erythroderma and pigmentation over her entire body. She thought her skin condition was atopic dermatitis, so had never consulted a doctor. She first noticed a subcutaneous nodule in 2011; thereafter, the number of nodules increased and spread to her whole body. She has suffered malaise and edematous legs since 2016.

A computed tomography scan revealed systemic lymphadenopathy and splenomegaly. ${ }^{18} \mathrm{~F}$-FDG PET/CT imaging revealed high ${ }^{18} \mathrm{~F}$-FDG uptake by systemic lymph nodes and skin. Laboratory tests revealed a white blood cell count of $61,200 / \mu \mathrm{L}(58.5 \%$ of which were abnormal lymphocytes with cerebriform nuclei). These cells were positive for CD 4 and CD25, but negative for CD3 and CD8. PCR analysis identified a clonal T-cell receptor $\beta$ and $\gamma$ chain gene rearrangement. Biopsies from bone marrow, cervical lymph nodes, and skin revealed infiltration by the same abnormal cells that were observed in peripheral blood (PB). Therefore, we made a diagnosis of SS, stage IVB (T4, N1, M1, B2).

The first treatment was narrowband UVB, which had no effect on the skin lesions. The second-line therapy, bexarotene, had no apparent therapeutic effects either; the number of subcutaneous nodules increased. Next, the patient received a cytotoxic regimen consisting of gemcitabine $\left(1,000 \mathrm{mg} / \mathrm{m}^{2}\right.$ on days 1 and 8$)$ plus dexamethasone (40 $\mathrm{mg}$ on days $\left.1-4\right)$. The subcutaneous nodules improved temporarily after 1 cycle of the chemotherapy; however, the subcutaneous nodules and edema deteriorated soon afterward. In addition, she developed cellulitis accompanied by stasis dermatitis, and so received antibiotic therapy.

The next therapy was vorinostat. The itching, subcutaneous nodules, and systemic lymphadenopathy improved after initiation of vorinostat. The number of lymphocytes circulating in the PB decreased from $37,700 / \mu \mathrm{L}$ prior to initiation of vorinostat to $13,700 / \mu \mathrm{L} 6$ months after. We considered that the treatment effect plateaued in November 2017 and decided to perform allogeneic HCT. She received allogeneic PB stem cell transplantation from her son (an HLA-haploidentical donor) in December 2017; this was due to a lack of an MSD or MUD. A reduced-intensity conditioning (RIC) regimen, consisting of fludarabine $\left(30 \mathrm{mg} / \mathrm{m}^{2}\right.$ on days -6 to -2 ), busulfan ( $3.2 \mathrm{mg} / \mathrm{kg}$ on days -4 to -3 ), and total body irradiation ( 4 Gy over 2 days [days -1 to 0 ]), was used. GVHD prophylaxis comprised PTCy (40 mg/kg on days 3-4), tacro- 


\section{Case Reports in Oncology}

Fig. 1. a Diffuse erythroderma, pigmentation, and many subcutaneous nodules on the arm before haplo-HCT. b The skin became smooth and soft, the pigmentation improved, and the subcutaneous nodules disappeared after haplo-HCT. HCT, hematopoietic cell transplantation.

\begin{tabular}{l|l}
\hline Case Rep Oncol 2020;13:1053-1058 \\
\hline DOI: 10.1159/000509347 & $\begin{array}{l}\text { ○ 2020 The Author(s). Published by S. Karger AG, Basel } \\
\text { www.karger.com/cro }\end{array}$ \\
\hline
\end{tabular}

Kanda-Kato et al.: Haploidentical HCT for Sézary Syndrome

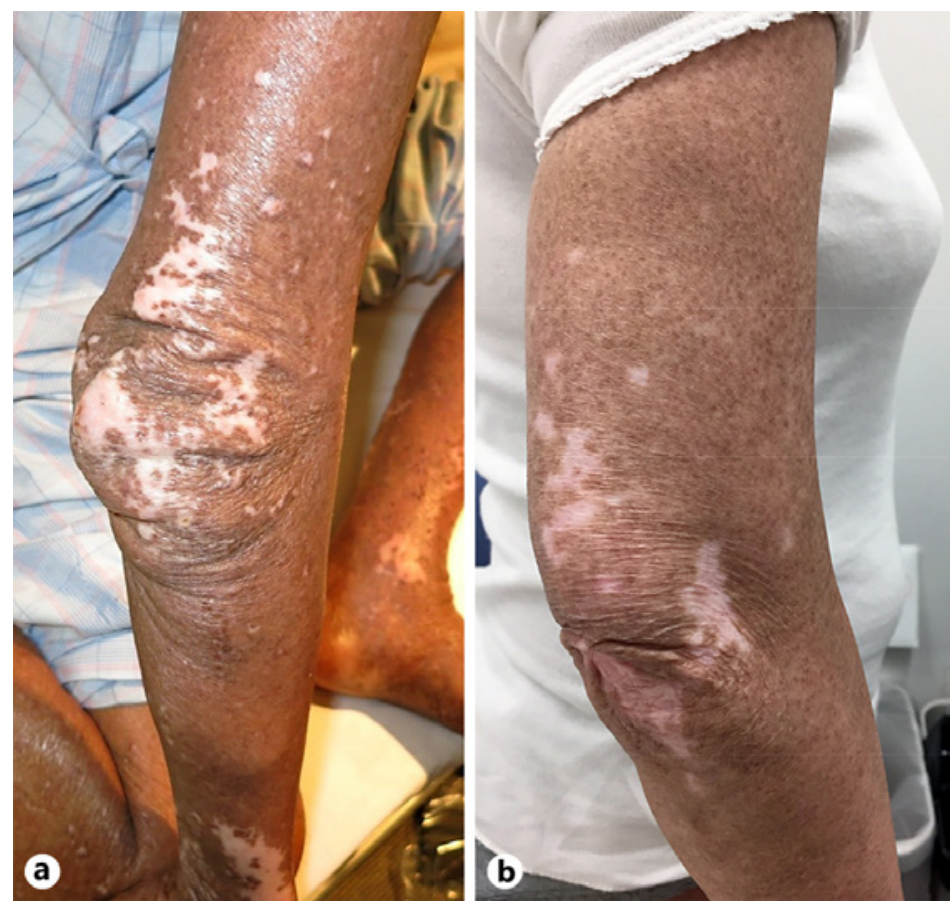

limus (FK; initiated at a dose of $0.02 \mathrm{mg} / \mathrm{kg}$ from day 5), and mycophenolate mofetil ( $30 \mathrm{mg} /$ $\mathrm{kg}$ from day 5). The number of infused CD34-positive cells was $9.1 \times 10^{6} / \mathrm{kg}$.

The patient developed a high fever on day 1 , which abated after PTCy was given on days $3-4$. She also developed febrile neutropenia on day 8 , which required antibiotic therapy. She achieved neutrophil engraftment on day 16 and then recovered from her febrile neutropenia. Cutaneous eruptions appeared on day 18 and expanded to her limbs. A skin biopsy suggested acute GVHD in the skin. We clinically diagnosed her with grade II acute GVHD (skin, stage 3; gut and liver, none). Corticosteroid therapy (methylprednisolone at $1 \mathrm{mg} / \mathrm{kg}$ ) was started to treat the acute GVHD, and the eruptions improved promptly and disappeared by day 30. Mycophenolate mofetil administration was stopped on day 36. FK and steroids were tapered gradually, and then stopped on day 214 without any relapse of GVHD. No tumor cells were detected in the PB and bone marrow 1 month after HCT. The subcutaneous nodules had almost disappeared, the skin pigmentation started to fade, and her skin became smoother and softer than it had been before HCT (Fig. 1). ${ }^{18}$ F-FDG PET/CT imaging revealed no ${ }^{18} \mathrm{~F}$-FDG uptake by the systemic lymph nodes and skin (Fig. 2). These findings indicate that she achieved CR after haplo-HCT. She is alive and has been in CR more than 24 months after HCT.

\section{Discussion}

Here, we presented a case of SS treated successfully by RIC haplo-HCT with PTCy. Allogeneic HCT is an effective treatment for advanced MF/SS and has the potential to achieve durable remission [5-9]. Most previous reports of allogeneic HCT for MF/SS used HCT from HLA-matched donors (MSD or MUD). However, in cases lacking HLA-matched donors, an alternative donor (such as an HLA-haploidentical donor or an unrelated cord blood [UCB] donor) must be found. 


\section{Case Reports in Oncology}

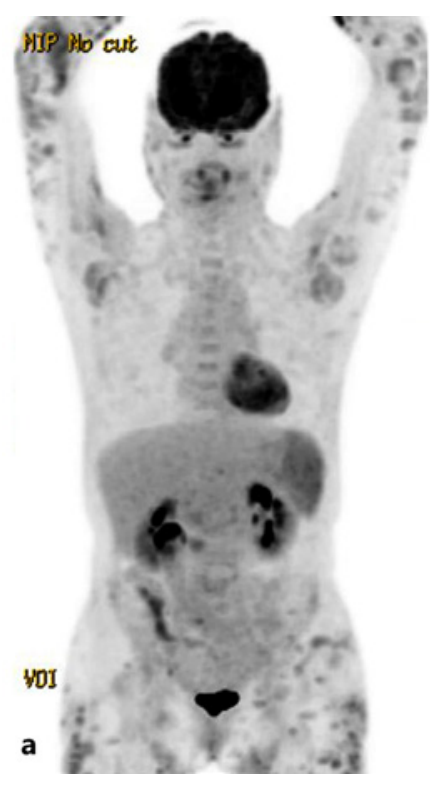

\begin{tabular}{l|l}
\hline Case Rep Oncol 2020;13:1053-1058 \\
\hline DOI: 10.1159/000509347 & $\begin{array}{l}\text { @ 2020 The Author(s). Published by S. Karger AG, Basel } \\
\text { www.karger.com/cro }\end{array}$ \\
\hline
\end{tabular}

Kanda-Kato et al.: Haploidentical HCT for Sézary Syndrome

Fig. 2. a ${ }^{18}$ F-FDG PET/CT image taken at the start of vorinostat therapy showing high ${ }^{18} \mathrm{~F}$-FDG uptake by the systemic lymph nodes and subcutaneous nodules. b ${ }^{18}$ F-FDG PET/CT image taken just before haplo-HCT showing a reduction in the number of lesions and reduced ${ }^{18} \mathrm{~F}$-FDG uptake. ${ }^{18} \mathrm{~F}$-FDG PET/CT image taken 3 months after haplo-HCT showing complete remission of the lesions. HCT, hematopoietic cell transplantation.

The rate of transplant-related mortality (TRM) after RIC haplo-HCT with PTCy is similar to that after HCT from matched donors, and even lower than that after a UCB transplantation [10]. Delayed engraftment and a higher risk of graft failure after UCB transplantation increase the risk of infectious complications. On the other hand, Ruggeri et al. [11] analyzed the Eurocord and EBMT databases, and reported that the rate of relapse after RIC haplo-HCT with PTCy was higher than that after UCB transplantation. However, a recent meta-analysis shows that the risk of relapse among those undergoing haplo-HCT with PTCy is significantly lower than that after UCB transplantation [12]. The phase II parallel Blood and Marrow Transplant Clinical Trials Network study shows that overall survival after haplo-HCT with PTCy is superior to that after UCB transplantation ( 62 vs. 54\% at 1 year after transplantation), with a lower TRM (7 vs. 24\%) [13].

Infectious complications, particularly cutaneous bacterial infections, are common among patients with MF/SS. In our case, the patient had diffuse erythroderma and her skin barrier had collapsed; she then developed cellulitis after gemcitabine treatment. Haplo-HCT has a lower incidence of severe infectious complications, leading to lower TRM, which is another reason for choosing haplo-HCT over a UCB transplantation.

There have been two case reports of patients with MF/SS receiving RIC haplo-HCT with PTCy. Méchineaud et al. [14] reported on a patient with SS who received a haploidentical bone marrow graft. The patient developed chronic GVHD in the skin 1 year after transplantation, which was treated effectively with topical betamethasone. She has been in CR for 30 months after transplantation. Baron et al. [15] reported on a patient with relapsed/refractory MF/SS who received a haploidentical bone marrow graft. Although the patient received many treatments, including interferon, narrowband UVB, bexarotene, total skin electron beam therapy, PD-1 inhibitor, mogamulizumab, romidepsin, and brentuximab, his disease was progressive. He received another course of total skin electron beam therapy before transplantation to debulk his extensive skin lesions. He overcame the transplantation without any infectious complications or GVHD, and has been in CR for 23 months. 
The present case also had progressive disease refractory to multiple therapies. Vorinostat improved the skin and lymph node lesions, and decreased Sézary cells in PB before transplantation. Vorinostat is a potent orally active inhibitor of histone deacetylase activity; it is noncross-resistant to other treatments and is effective for some patients with multi-drug-resistant disease. Vorinostat has a very low incidence of infectious complications, giving it a considerable advantage over conventional chemotherapy such as gemcitabine. This is probably due to the lack of need for venous access and the absence of major immunosuppression $[16,17]$. A very short response duration (median 168 days) is the most important problem associated with vorinostat [18]. Here, we chose the patient's haploidentical son as an alternative donor, which made it possible to perform allogeneic HCT promptly and before disease progression.

In conclusion, this case of refractory SS was treated successfully by haplo-HCT with PTCy, which achieved durable remission without severe complications such as infection. Haplo-HCT with PTCy is an effective and safe treatment for patients with MF/SS, as well as other allogeneic HCT from matched donors. It is worth considering this therapy when a patient lacks a matched donor. Further studies are needed to clarify the optimal use of haplo-HCT for MF/SS.

\section{Statement of Ethics}

The case was approved by the clinical ethics committee of the Kobe Medical Center General Hospital, and the patient signed a written informed consent form to publish her case (including publication of images).

\section{Conflict of Interest Statement}

The authors have no conflicts of interest to declare.

\section{Funding Sources}

The authors declare that there was no funding for this case report.

\section{Author Contributions}

Madoka Kanda-Kato was the hematologist involved in the case and wrote the case report. Satoshi Yoshioka was also involved in the case and helped in writing and editing the case report. Takayuki Ishikawa supervised the case and helped in writing and editing the case report. All authors read and approved the final manuscript.

\section{References}

1 Wilcox RA. Cutaneous T-cell lymphoma: 2017 update on diagnosis, risk-stratification, and management. Am J Hematol. 2017;92(10):1085-102.

2 Trautinger F, Eder J, Assaf C, Bagot M, Cozzio A, Dummer R, et al. European Organisation for Research and Treatment of Cancer consensus recommendations for the treatment of mycosis fungoides/Sézary syndrome - Update 2017. Eur J Cancer. 2017;77:57-74.

3 Iqbal M, Reljic T, Ayala E, Sher T, Murthy H, Roy V, et al. Efficacy of allogeneic hematopoietic cell transplantation in cutaneous t cell lymphoma: results of a systematic review and meta-analysis. Biol Blood Marrow Transplant. 2020;26(1):76-82. 
4 Dietrich S, Finel H, Martinez C, Tischer J, Blaise D, Chevallier P, et al. Post-transplant cyclophosphamide-based haplo-identical transplantation as alternative to matched sibling or unrelated donor transplantation for nonHodgkin lymphoma: a registry study by the European Society for Blood and Marrow Transplantation. Leukemia. 2016;30(10):2086-9.

5 Duarte RF, Canals C, Onida F, Gabriel IH, Arranz R, Arcese W, et al. Allogeneic hematopoietic cell transplantation for patients with mycosis fungoides and Sezary syndrome: a retrospective analysis of the Lymphoma Working Party of the European Group for Blood and Marrow Transplantation. J Clin Oncol. 2010;28(29): 4492-9.

6 Duvic M, Donato M, Dabaja B, Richmond H, Singh L, Wei W, et al. Total skin electron beam and non-myeloablative allogeneic hematopoietic stem-cell transplantation in advanced mycosis fungoides and Sézary syndrome. J Clin Oncol. 2010;28(14):2365-72.

7 Delioukina M, Zain J, Palmer JM, Tsai N, Thomas S, Forman S. Reduced-intensity allogeneic hematopoietic cell transplantation using fludarabine-melphalan conditioning for treatment of mature T-cell lymphomas. Bone Marrow Transplant. 2012;47(1):65-72.

8 Lechowicz MJ, Lazarus HM, Carreras J, Laport GG, Cutler CS, Wiernik PH, et al. Allogeneic hematopoietic cell transplantation for mycosis fungoides and Sézary syndrome. Bone Marrow Transplant. 2014;49(11):1360-5.

9 Hosing C, Bassett R, Dabaja B, Talpur R, Alousi A, Ciurea S, et al. Allogeneic stem-cell transplantation in patients with cutaneous lymphoma: updated results from a single institution. Ann Oncol. 2015;26(12):2490-5.

10 Kekre N, Antin JH. Cord blood versus haploidentical stem cell transplantation for hematological malignancies. Semin Hematol. 2016;53(2):98-102.

11 Ruggeri A, Labopin M, Sanz G, Piemontese S, Arcese W, Bacigalupo A, et al. Comparison of outcomes after unrelated cord blood and unmanipulated haploidentical stem cell transplantation in adults with acute leukemia. Leukemia. 2015;29(9):1891-900.

12 Poonsombudlert K, Kewcharoen J, Prueksapraopong C, Limpruttidham N. Post transplant cyclophosphamide based haplo-identical transplant versus umbilical cord blood transplant; a meta-analysis. Jpn J Clin Oncol. 2019;49(10):924-31.

13 Brunstein CG, Fuchs EJ, Carter SL, Karanes C, Costa LJ, Wu J, et al. Alternative donor transplantation after reduced intensity conditioning: results of parallel phase 2 trials using partially HLA-mismatched related bone marrow or unrelated double umbilical cord blood grafts. Blood. 2011;118(2):282-8.

14 Méchineaud M, Mercier M, Le Corre Y, Croué A, Ifrah N, Martin L. Cutaneous and systemic T-cell lymphoma treated with haploidentical bone marrow transplantation [in French]. Ann Dermatol Venereol. 2018;145(67):439-44.

15 Baron MK, Osborn JD, Tao R, Lee CJ. Haploidentical hematopoietic cell transplantation for mycosis fungoides/ Sézary syndrome. Leuk Lymphoma. 2020;61(1):231-3.

16 Olsen EA, Kim YH, Kuzel TM, Pacheco TR, Foss FM, Parker S, et al. Phase IIb multicenter trial of vorinostat in patients with persistent, progressive, or treatment refractory cutaneous T-cell lymphoma. J Clin Oncol. 2007; 25(21):3109-15.

17 Kogge A, Volteau C, Saint-Jean M, Peuvrel L, Brocard A, Knol AC, et al. Vorinostat for refractory or relapsing epidermotropic T-cell lymphoma: a retrospective cohort study of 15 patients. Acta Derm Venereol. 2015; 95(1):72-7.

18 Mann BS, Johnson JR, Cohen MH, Justice R, Pazdur R. FDA approval summary: vorinostat for treatment of advanced primary cutaneous T-cell lymphoma. Oncologist. 2007;12(10):1247-52. 